\title{
RADIATION INTERCEPTION, LIGHT EXTINCTION COEFFICIENT AND LEAF AREA INDEX OF WHEAT (Triticum aestivum L.) CROP AS INFLUENCED BY ROW ORIENTATION AND ROW SPACING
}

\author{
M.M. Lunagaria ${ }^{1}$ and A.M. Shekh ${ }^{1}$
}

\begin{abstract}
A field experiment was conducted at the $B$ A College of Agriculture, Anand Agricultural University, Anand (India) $\left(22^{\circ} 35^{\prime} \mathrm{N}, 7^{\circ} 55^{\prime} \mathrm{E}\right.$; $\left.45.1 \mathrm{~m} \mathrm{MSL}\right) d u r i n g ~ r a b i$ (winter) season of 2003-2004 on a sandy loam soil to study the effect of row orientation and row spacing on radiation interception, Leaf Area Index and Light extinction coefficient in Wheat (Triticum aestivum L.) cv. GW-496 under two dates of sowing. The PAR values in terms of incident/incoming PAR and transmitted PAR at the field were measured after canopy development (i.e. 23 Days after sowing) at 10 day intervals at 0900-1000 h, 1200-1300 h and 1500-1600 h in a day with a Sun San Canopy Analysis System (Delta-T Devices, UK). LAI was also measured directly by the Sun Scan Canopy Analysis System at noon. The instantaneous values were averaged for that day and were converted to $\mathrm{MJm}^{-2}$ day ${ }^{-1}$. Solar radiation was recorded by a Pyranometer. The conversion of the daily solar radiation to PAR was made by employing a 0.5 fraction. Narrow NS (North-South) rows in general produced higher LAI throughout the growing season. NS row with narrow spacing was the most effective treatment in relation to the accumulated IPAR values, although the differences in the values corresponding to other treatments were not remarkable. The fluctuations in extinction coefficient $(k)$ values were less random in NS rows than those corresponding ones for EW rows.
\end{abstract}

Key words: Extinction coefficient (k), Leaf Area Index (LAI), Radiation interception fraction (F), Row spacing, Row orientation, Wheat

\section{INTRODUCTION}

Radiation and moisture are basic meteorological parameters of significance to agriculture. Under potential conditions, with adequate moisture and fertility, radiation plays the role of a decisive factor for crop growth and development. Thus, manipulation of radiant energy within a crop field by an appropriate adoption of crop stand geometry, like row orientation and row spacing can provide a means to create light saturated conditions for crop canopy for the purpose of efficient harvest of solar energy for agricultural production.
The present investigation was undertaken to study the effect of row orientation and row spacing on Radiation interception, Leaf Area Index and Light extinction coefficient of Wheat crop (Triticum aestivum L.) in Anand condition.

\section{MATERIAL AND METHODS}

A field experiment was conducted on the Agronomy farm of B A College of Agriculture, AAU, Anand (India) $\left(22^{\circ} 35^{\prime} \mathrm{N}, \quad 72^{\circ} 55^{\prime} \mathrm{E} ; 45.1 \mathrm{~m}\right.$ above Mean Sea Level) during the rabi season of 2003-2004. The soil was sandy loam (Alluvial soil, Orchrespt), locally known as "Goralu Soil". The cultivar GW-496 of wheat crop was 
sown in two orientation ( $\mathrm{R}_{1}$ : NorthSouth and $\mathrm{R}_{2}$ : East-West), two row spacings $\left(\mathrm{S}_{1}: 15 \mathrm{~cm}\right.$ and $\left.\mathrm{S}_{2}: 22.5 \mathrm{~cm}\right)$ and two dates of sowing $\left(\mathrm{D}_{1}: 12\right.$ November and $\mathrm{D}_{2}: 27$ November of 2003). The experiment was laid out in Split plot design with four replications. The Photosynthetically Active Radiation (PAR) was measured at 10 day intervals with SunScan Canopy Analysis System (Delta-T Devices, UK) from 23 Days After Sowing(DAS). PAR was measured between 0900-1000 h, 1200-1300 h and $1500-1600 \mathrm{~h}$ in a day. Transmitted PAR was measured by keeping the Sunscan probe perpendicular to the rows at ground level and incoming PAR was measured with Beam Fraction sensor (BF2) of the system at top of the crop canopy. To determine daily incident PAR, Solar radiation was recorded at the Pyranometer sensor installed by the India Meteorological Department (IMD) in an agrometeorological observatory located near the experimental site. The conversion of solar radiation to PAR was done by adopting the multiplier 0.5 (Monteith and Unsworth, 1990; Campbell and Norman, 1998). The Leaf Area Index (LAI) was measured directly by the Sun Scan Canopy Analysis System at noon on the day obtaining PAR measurements. The Radiation interception fraction $(F)$ of Photosynthetically Active Radiation (PAR) was calculated as the ratio of the PAR intercepted (IPAR) by plants to the PAR incident above canopy.

$$
\mathrm{F}=\frac{\phi \mathrm{IPAR}}{\phi \mathrm{PAR}}
$$

The extinction coefficient is a measure of extinction of any transmitted light in the crop canopy and is calculated as

$$
\mathrm{k}=\left[\frac{-\ln \left(\frac{\mathrm{PAR}_{\mathrm{t}}}{\mathrm{PAR}_{\mathrm{i}}}\right)}{\mathrm{LAI}}\right]
$$

Where, $\mathrm{PAR}_{\mathrm{t}}=\mathrm{PAR}$ transmitted (at bottom of canopy)

$\mathrm{PAR}_{\mathrm{i}}=\mathrm{PAR}$ incoming (at top of canopy)

$\mathrm{LAI}=$ Leaf Area Index

\section{RESULTS AND DISCUSSION}

\section{Leaf Area Index}

The variation in leaf area index with the progress of the season has been depicted in Fig.1, separately for the two dates of sowing in conjunction with pertinent treatment combinations.

Narrow NS rows in general produced higher LAI throughout the growing season of the experiment. Interception of radiation is mainly dependent on leaf area. The peak values of LAI recorded in the narrow NS rows were 5.1 and 6.3 in the respective sowing dates. It was clear from the trends that in all the treatments there was a gradual rise in the LAI till the crop reached the flowering stage. Thereafter LAI continued to decline until the crop attained the maturity stage. The differences in the LAI values corresponding to other treatments were not quite marked and neither did they depict any definite pattern. LAI was found to be vary with the stage of growth of the crop only. This meant that the other treatments as adopted in the study were not effective in influencing LAI development. 
Table 1: Seasonal mean of Leaf Area Index (LAI) as affected by different treatments

\begin{tabular}{cc}
\hline Treatment & LAI \\
\hline $\mathrm{D}_{1} \mathrm{~S}_{1} \mathrm{R}_{1}$ & 3.26 \\
$\mathrm{D}_{1} \mathrm{~S}_{1} \mathrm{R}_{2}$ & 2.49 \\
$\mathrm{D}_{1} \mathrm{~S}_{2} \mathrm{R}_{1}$ & 2.67 \\
$\mathrm{D}_{1} \mathrm{~S}_{2} \mathrm{R}_{2}$ & 2.55 \\
$\mathrm{D}_{2} \mathrm{~S}_{1} \mathrm{R}_{1}$ & 3.70 \\
$\mathrm{D}_{2} \mathrm{~S}_{1} \mathrm{R}_{2}$ & 3.23 \\
$\mathrm{D}_{2} \mathrm{~S}_{2} \mathrm{R}_{1}$ & 3.38 \\
$\mathrm{D}_{2} \mathrm{~S}_{2} \mathrm{R}_{2}$ & 2.96 \\
\hline
\end{tabular}

A high LAI was recorded in narrow NS rows during both the sowing dates (3.26 and 3.7, in respective sowing dates) (Table. 1). Wide NS rows yielded the values of 2.67 and 3.38 , in respective sowing dates, which were next in order to those for narrow NS rows. The EW rows produced low LAI in general. The pattern of trend in LAI was found to be analogous to that in mean radiation interception by the pertinent treatment combination. This result establishes a close interdependence between LAI and radiation interception.

\section{Radiation Interception Fraction (F)}

The parameter representing the fraction of PAR intercepted by the crop was studied in terms of the daily pattern at specified times of the day as averaged for the crop growing season as a whole and also in terms of seasonal trends as expressed in relation to Days after sowing (DAS), in section I and II respectively.

\section{Day time variation in Radiation interception}

Seasonal averages of the interception fraction of PAR (F) between 0900$1000 \mathrm{~h}, 1200-1300 \mathrm{~h}$ and 1500-1600 h are shown in Fig.2. In all the treatments $\mathrm{F}$ was higher at $0900-1000$ $\mathrm{h}$ than 1200-1300 $\mathrm{h}$ and 1500-1600 $\mathrm{h}$ of the day.

This result is in conformity with that reported in past experimental studies (Tsubo et al., 2001; Muchow et al., 1982). The $F$ values were recorded as high as 0.87 and 0.92 for widely spaced NS rows $(22.5 \mathrm{~cm}$ apart), during morning hour. There was no much difference in interception among treatments during the morning and afternoon hours while at the noon hours there was a marked difference in interception. There was maximum interception in the narrow NS rows (15 $\mathrm{cm}$ apart) at 1200-1300 $\mathrm{h}$. This value was succeeded by the one for the widely spaced NS rows. There was the more interception (0.75) in first sowing and less (0.73) in the second sowing in case of wide EW rows than that in case of the narrow EW rows (0.69 and 0.75 in relation to the respective sowing time). During the $1500-1600 \mathrm{~h}$ period wide EW rows had the highest $F(0.87)$ in the first sowing while narrow EW rows gave a value of 0.86 in the second sowing. The other treatments followed a similar pattern but with negligible difference. 

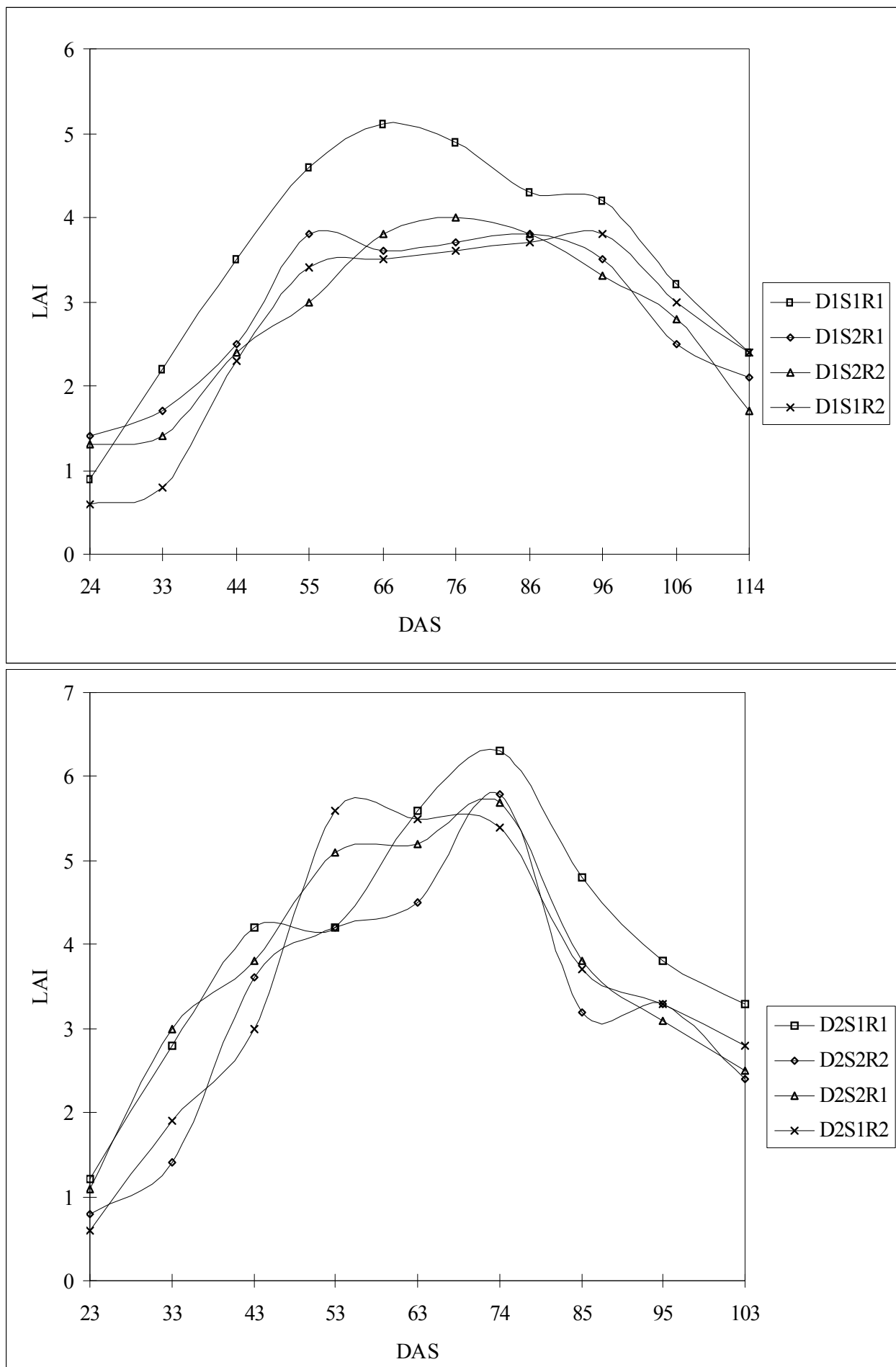

Fig.1 Seas onal trend of wheat crop LAI for the treatments 

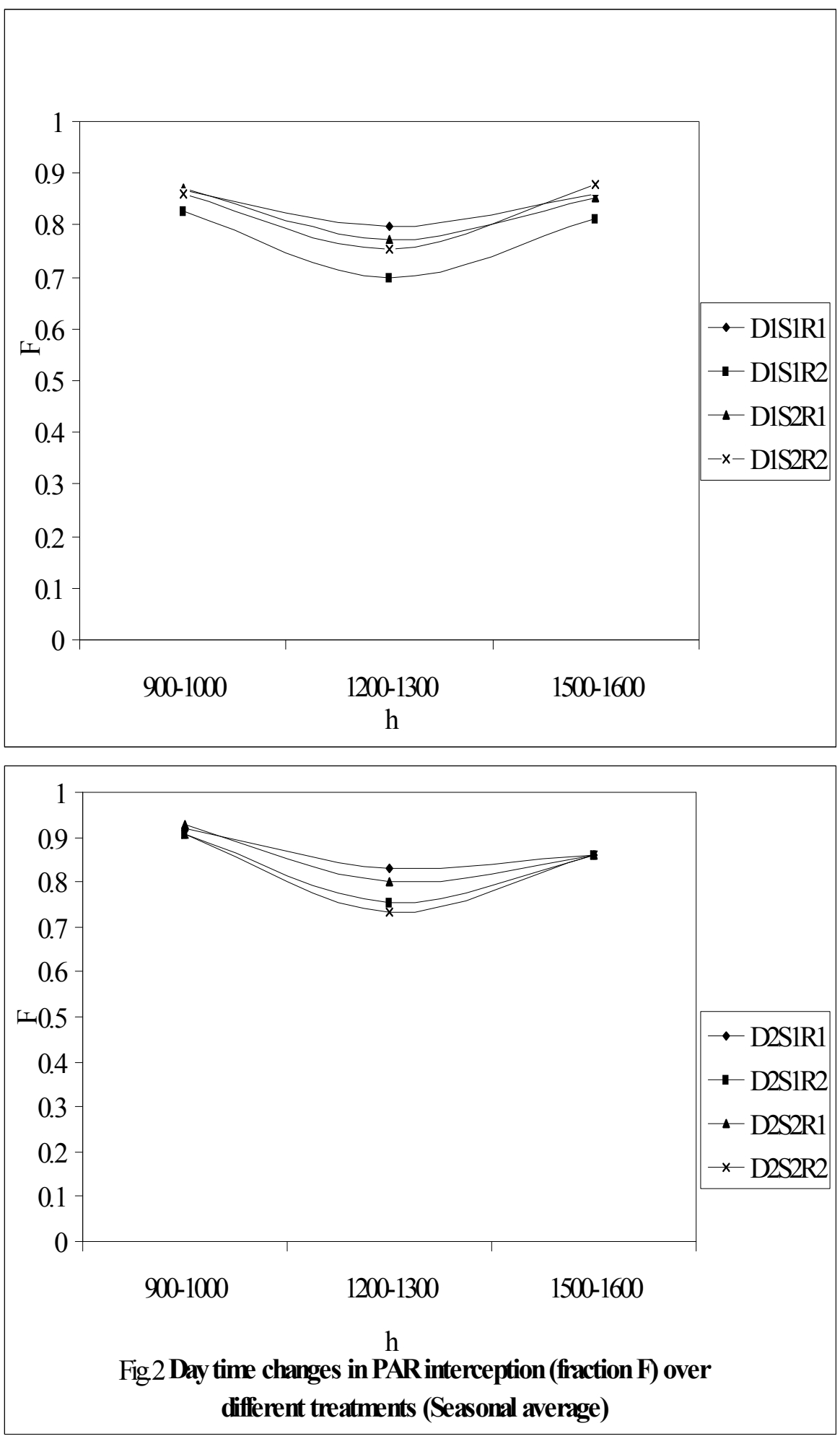
The value of the Radiation Interception Fraction $(\mathrm{F})$ depends on the inclination of the solar rays for a given leaf shape, plant height and plant density in the field. The high values of $\mathrm{F}$ for the periods $0900-1000 \mathrm{~h}$ and $1500-1600 \mathrm{~h}$ were therefore due to solar rays being more inclined i.e. making low angle with respect to horizontal than those in the noon hours, 1200-1300 $\mathrm{h}$ when they are almost vertically incident. More inclination causes the beam to be spread over relatively large area and hence the number of plants encountered per square unit area is more and hence more interception.

\section{Seasonal Radiation interception trends}

The seasonal PAR interception fraction (F) is presented in Fig.3. The trend of the values of seasonal interception fraction (F) had shown more or less identical pattern in all the treatments. There was a continuous increase in $\mathrm{F}$ during the canopy development stage till the booting stage and after that there was a 'plateau'.

The values declined during the physiological maturity stage. This indicated that the interception was mainly dependent on the canopy leaf area. A similar observation has also been reported in the past (Biscoe and Gallagher, 1977). Radiation interception varied from emergence to harvesting (Natarajan and Willey, 1980, 1985; Sivakumar and Virmani, 1980; Reddy and Willey, 1981; Watiki et al., 1993). This result is obvious on the basis of the fact that canopy leaf area index also varies from emergence to harvesting.

Table 2: Mean seasonal interception fraction $F$ for different treatments

\begin{tabular}{cc}
\hline Treatment & Mean F \\
\hline $\mathrm{D}_{1} \mathrm{~S}_{1} \mathrm{R}_{1}$ & 0.839 \\
$\mathrm{D}_{1} \mathrm{~S}_{1} \mathrm{R}_{2}$ & 0.779 \\
$\mathrm{D}_{1} \mathrm{~S}_{2} \mathrm{R}_{1}$ & 0.829 \\
$\mathrm{D}_{1} \mathrm{~S}_{2} \mathrm{R}_{2}$ & 0.825 \\
$\mathrm{D}_{2} \mathrm{~S}_{1} \mathrm{R}_{1}$ & 0.863 \\
$\mathrm{D}_{2} \mathrm{~S}_{1} \mathrm{R}_{2}$ & 0.821 \\
$\mathrm{D}_{2} \mathrm{~S}_{2} \mathrm{R}_{1}$ & 0.848 \\
$\mathrm{D}_{2} \mathrm{~S}_{2} \mathrm{R}_{2}$ & 0.812 \\
\hline
\end{tabular}


The mean values of $F$ as shown in Table 2 indicated that the narrow NS rows had high interception in both sowings $(83.9 \%$ and $86.3 \%$ during respective sowings). The treatments involving the wider NS rows yielded $\mathrm{F}$ values of $82.9 \%$ for first and $84.8 \%$ for second sowing. Narrow EW rows had the poorest interception (77\%) for the first date of sowing while wide EW rows had the poorest interception $(81 \%)$ in case of second sowing. The second sowing had more interception because of high LAI and luxuriant growth, as indicated in LAI values.

The highest $F$ value was observed in narrow NS rows i.e.0.97 (Peak value in the growth season) for both sowings, and the treatment showed more interception for the whole of the growing season compared to other treatments. As the $\mathrm{F}$ was high in the narrow NS rows, the accumulated IPAR was maximum in these treatments $\left(561.7 \mathrm{MJ} \mathrm{m}^{-2}\right.$ and 644.1 MJ $\mathrm{m}^{-2}$, in respective sowings). The values of accumulated IPAR for wide NS rows were $552.2 \mathrm{MJ} \mathrm{m}^{-2}$ and 633.6 MJ $\mathrm{m}^{-2}$, in respective sowing. There was only negligible difference in values of accumulated IPAR for EW rows when compared with those corresponding ones for NS rows. It appeared from these results that NS row orientation with narrow spacing was the most effective treatment in relation to the accumulated IPAR values, although the differences in the values corresponding to other treatments were not markedly. Almost all the treatments have behaved, more or less identically in relation to the seasonal trend in PAR interception.

\section{Light Extinction Coefficient (K)}

There was a significant correlation between natural log scale of radiation transmission and LAI in all the treatments $\left(r^{2} \geq 0.89\right)$ (Fig.4). The slope is known as the extinction coefficient (k), explains the average projection area of canopy elements onto a horizontal surface (Campbell and Norman, 1989). The erect leaves have low $\mathrm{k}$ value. There was no noticeable difference in the trend of $\mathrm{k}$ values during the early stages of the growth among different treatments. The value of $\mathrm{k}$ that could be taken common for all the treatments during early stages of the crop growth was close to 0.7 . This value indicated that the crop canopy was nearly horizontally distributed. 

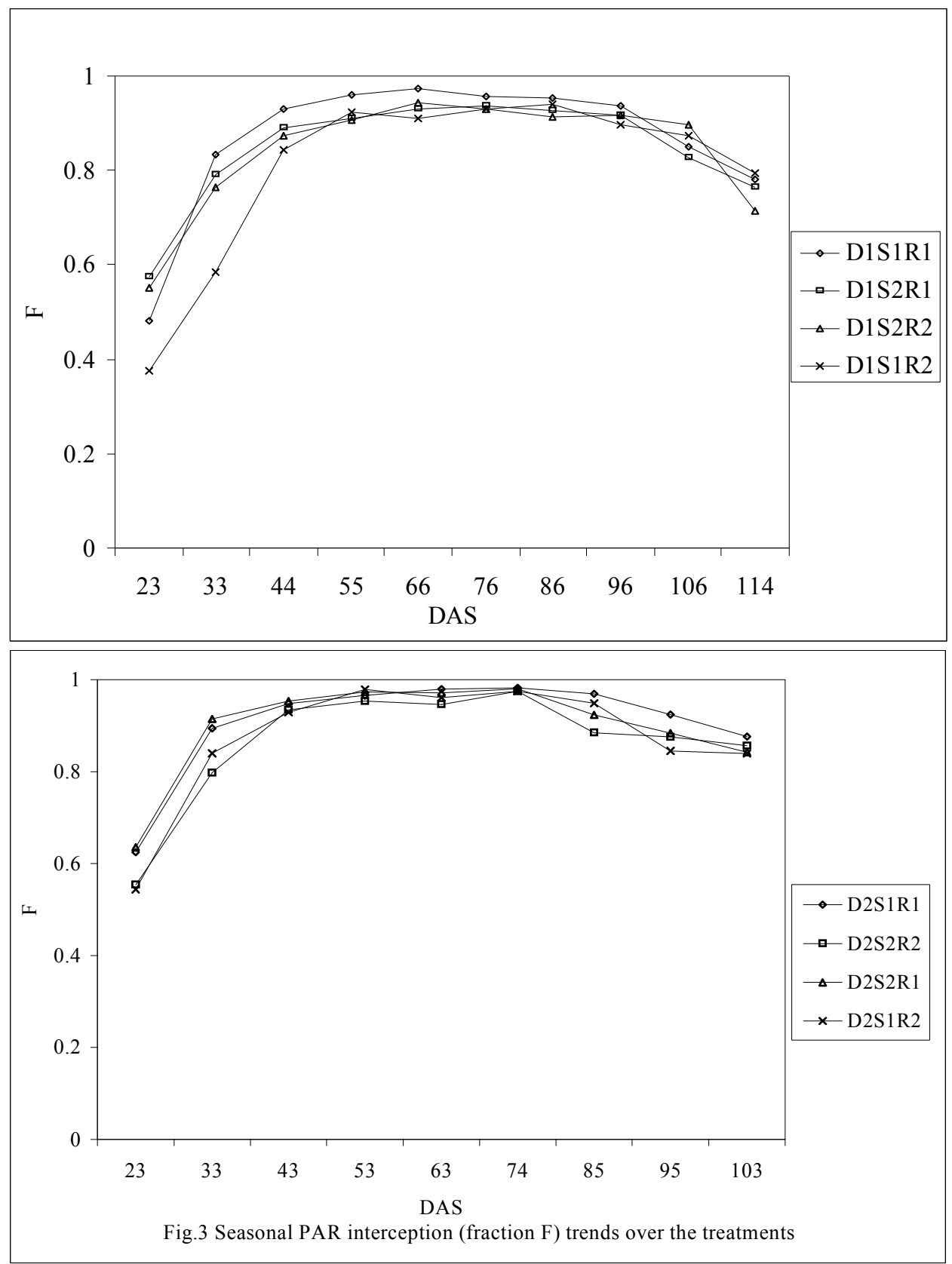

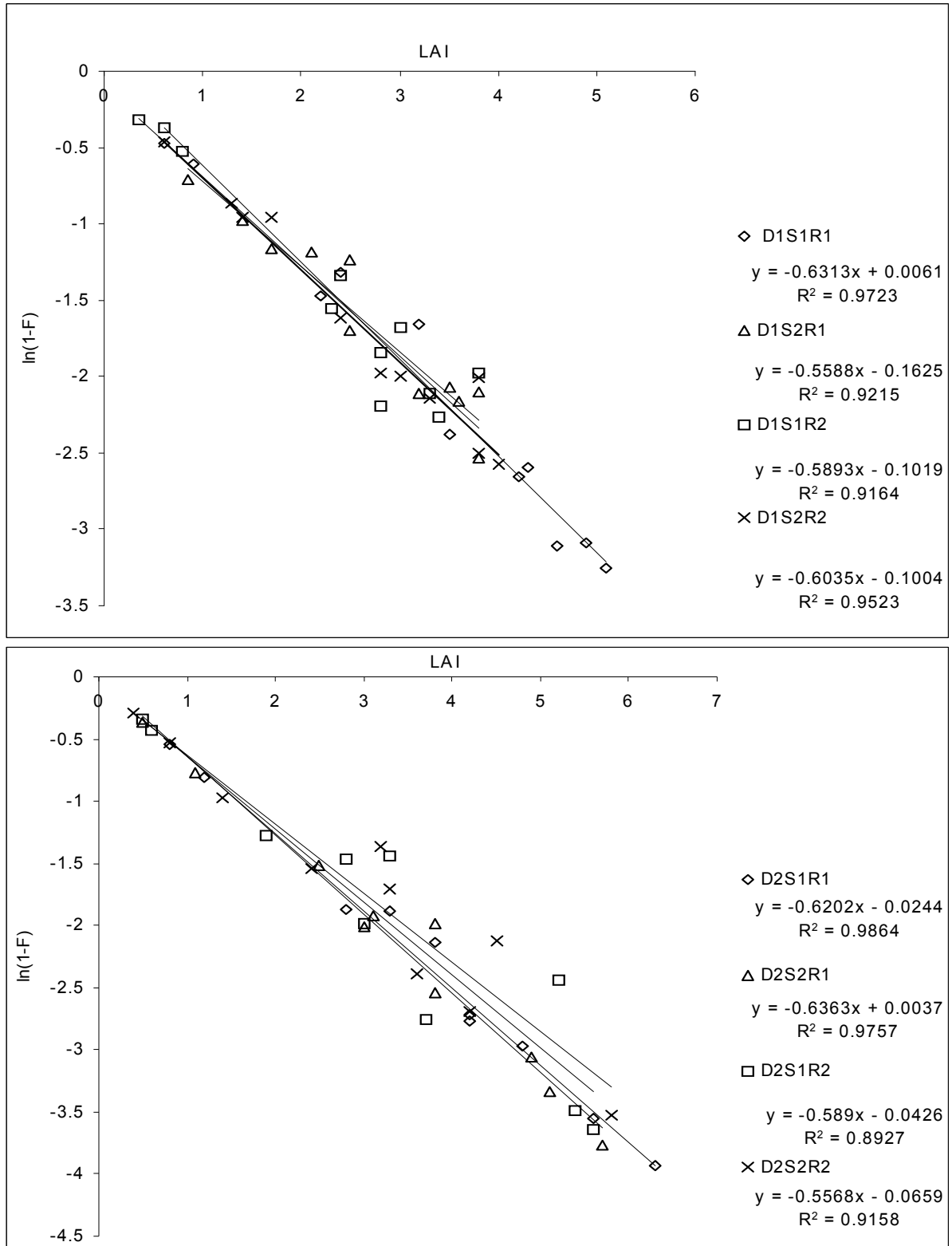

Fig.4 Light/Canopy Extinction Coefficient of the treatments 

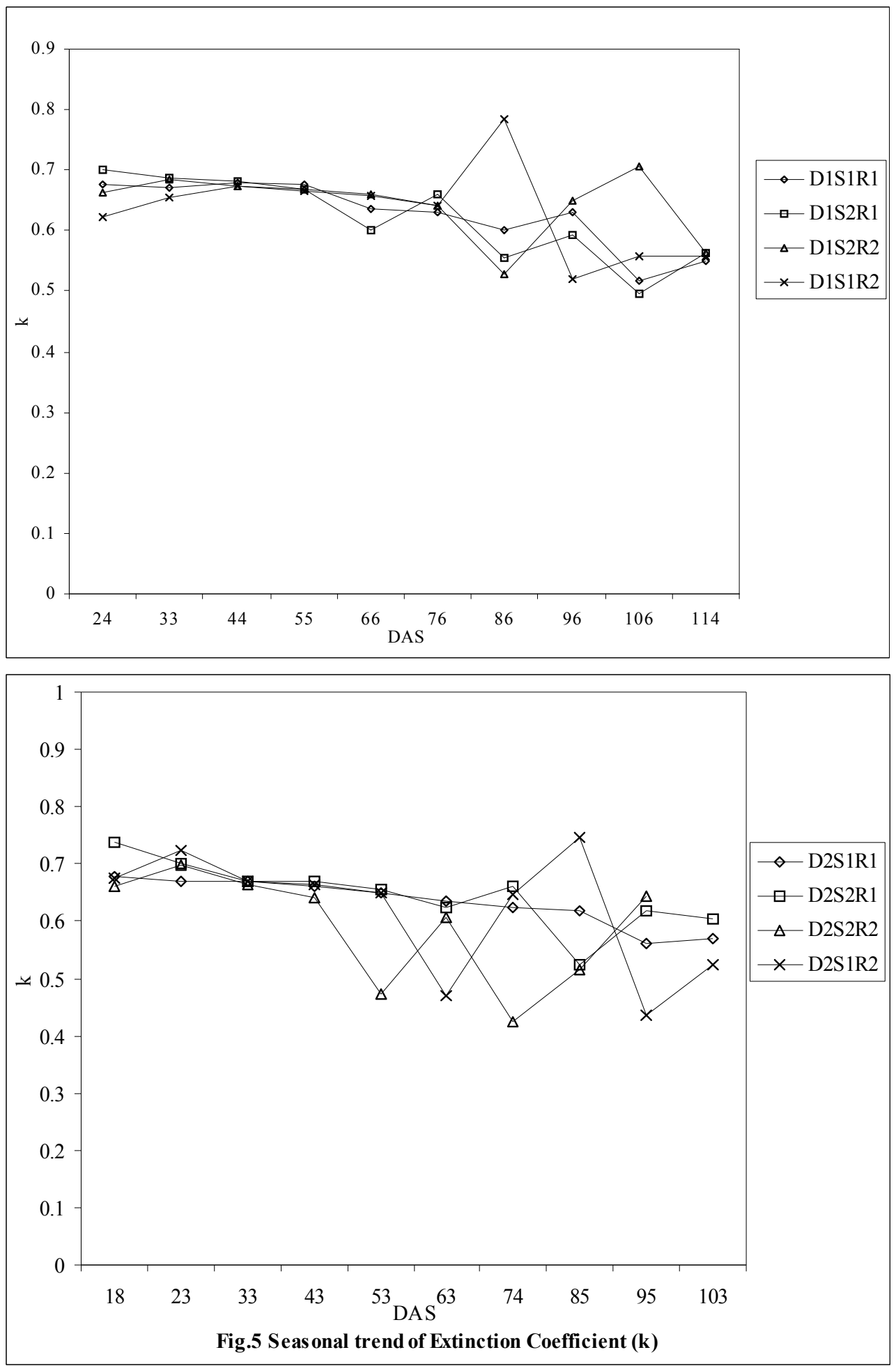
An examination of the seasonal trend of $\mathrm{k}$ as depicted on Fig.5 revealed that there was a gradual drop in the $\mathrm{k}$ values with the advancement of the crop growth till maturity. There were noticeable fluctuations in the values after the flowering stage. These fluctuations were because of the changes in the canopy properties like LAI, leaf angle and senescence. A striking feature that came to be noticed was that in both the sowing times, NS rows (narrow and wide) did not have much fluctuations in $\mathrm{k}$ values while EW rows (narrow and wide) showed comparatively more fluctuations, indicating the pronounced changes in canopy structure in case of EW orientation in comparison with that in NS orientation. Second date of sowing also showed a higher fluctuation in the values of canopy extinction coefficient and it is also tune with the changes in LAI (Fig.1), indicates there were more changes in the canopy structure.

The statistical analysis of the yield attributes revealed that, in general, there was no significant influence of the various radiation regimes under different row orientation and spacing on the crop performance.

\section{CONCLUSIONS}

The experimental findings obtained during the course of the present investigation revealed that high mean LAI was recorded in narrow NS rows during both sowing dates. Wide NS rows succeeded this treatment and the EW rows produced lower LAI. The highest interception was recorded during the morning hours and there was a negligible difference among the treatments in this respect. The difference in the interception was higher during noon time, and narrow NS rows intercepted higher PAR (0.92). Wide NS rows and wide EW rows had higher solar radiation interception than that narrow EW rows at noon hours. The seasonal average of the interception fraction indicated more or less identical results that representing different treatments, narrow NS oriented row had highest interception fraction value i.e.0.86 and while in narrow EW rows had the poorest value $(0.77)$. The NS rows (narrow and wide) did not show much fluctuation in the values of $K$ (extinction coefficient), while EW rows (narrow and wide) showed comparatively more fluctuations, indicating the changes in canopy structure.

\section{References}

Biscoe, P.V. and J.N. Gallagher, (1977). Weather, dry matter production and yield. In: Lsndsberg, J.J., Cutting, C.V.(Eds.), Environmental Effects on crop physiology. Academic press, London.pp.75-100

Campbell, G.S. and J.M. Norman, (1989). The description and measurement of plant canopy structure. In: G. Russel, , B. Marshall, , P.G. Jarvis, (Eds), Plant Canopies: Their Growth, Form and Function. Cambridge University Press, Cambridge,pp.1-19.

Campbell, G.S. and J.M. Norman, (1998). An Introduction to Environmental Biophysics, $2^{\text {nd }}$ Edition, Springer, New York.

Monteith, J.L. and M.Unsworth, (1990). Principles of Environmental Physics, $2^{\text {nd }}$ Edition Edward, Arnold, London. 
Muchow, R.C., D.B. Coates, G.L. Wilson, and M.A. Foale, (1982). Growth and productivity of irrigated sorghum bicolor in Northern Australia: I. Plant density and arrangement effects on light interception and distribution, and grain yield, in the hybrid Texas 610SR in low and medium latitudes. Autralian Journal of Agricultural Research, v.33, pp.773-784.

Natarajan, M., and R.W. Willey, (1980). Sorghum-pigeonpea intercropping and the effects of plant population density. 2. Resource use. J.Agric. Sci. Camb.95, pp.59-65

Natarajan, M., and R.W. Willey, (1985). Effects of row arrangement on light interception and yield in sorghum-pigeonpea intercropping. J.Agric. Sci.Camb.104, pp.263-270

Reddy, M.S. and R.W. Willey, 1981. Growth and resource use studies in an intercrop of pearl millet/groundnut. Field Crops Res. 4, pp.13-24.

Sivakumar, M.V.K., S.M. Virmani, (1980). Growth and resource use of maize,pigeonpea and maize/pigeonpea intercrop in an operational research watershed. Exp.Agric.16, pp.377-386

Tsubo, M., S. Walker, and E. Mukhala, (2001). Comparison of radiation use efficiency of mono-/intercropping systems with different row orientations. Field Crop Research.71,pp.17-29

Watiki, J.M., S. Fukai, J.A. Bandia, and B.A. Keating, (1993). Radiation interception and growth of maize/cowpea intercrop as affected by maize plant density and cowpea cultivar. Field Crops Res. 35, pp.123-133. 